\title{
Bias dependence of laser terahertz emission nanoscopy
}

Pizzuto, Angela; Klarskov, Pernille; Mittleman, Daniel M.

Published in:

CLEO: Applications and Technology 2018

Link to article, DOI:

10.1364/CLEO_AT.2018.JM1A.3

Publication date:

2018

Document Version

Publisher's PDF, also known as Version of record

Link back to DTU Orbit

Citation (APA):

Pizzuto, A., Klarskov, P., \& Mittleman, D. M. (2018). Bias dependence of laser terahertz emission nanoscopy. In CLEO: Applications and Technology 2018 (Vol. 2018). IEEE. Optics Infobase Conference Papers https://doi.org/10.1364/CLEO AT.2018.JM1A.3

\section{General rights}

Copyright and moral rights for the publications made accessible in the public portal are retained by the authors and/or other copyright owners and it is a condition of accessing publications that users recognise and abide by the legal requirements associated with these rights.

- Users may download and print one copy of any publication from the public portal for the purpose of private study or research.

- You may not further distribute the material or use it for any profit-making activity or commercial gain

- You may freely distribute the URL identifying the publication in the public portal 


\title{
Bias Dependence of Laser Terahertz Emission Nanoscopy
}

\author{
Angela Pizzuto $^{1}$, Pernille Klarskov ${ }^{2,3}$, and Daniel M. Mittleman ${ }^{2}$ \\ ${ }^{I}$ Department of Physics, Brown University, Providence, RI 02903, USA \\ ${ }^{2}$ Department of Electrical and Computer Engineering, Brown University, Providence, RI 02903, USA \\ ${ }^{3}$ DTU Fotonik - Department of Photonics Engineering, Technical University of Denmark, \\ 2800 Kgs. Lyngby, Denmark \\ angela_pizzuto@brown.edu
}

\begin{abstract}
We demonstrate depletion of terahertz emission from semiconductors by applying a DC bias between a substrate and an AFM probe operating in tapping mode. The depletion is strongly dependent on the probe tapping amplitude. (C) 2018 The Author(s)

OCIS codes: (180.4243) Near-Field Microscopy; (320.7130) Ultrafast Processes in Condensed Matter, Including Semiconductors
\end{abstract}

\section{Introduction}

Laser terahertz emission microscopy (LTEM) uses femtosecond optical pulses to induce terahertz emission from a material to probe its charge carrier dynamics. Using a scattering-type scanning near-field optical microscope (sSNOM) with a small conductive atomic force microscopy (AFM) probe [1] allows for confinement of the incoming laser beam as well as the generated $\mathrm{THz}$ field to a subwavelength scale, increasing imaging resolution by up to three orders of magnitude compared to the diffraction limit for conventional LTEM [2]. In this study, we apply a DC bias between the near-field microscope tip and selected semiconductor wafers to observe its effects on the emitted $\mathrm{THz}$ radiation as well as its dependence on the tip tapping amplitude.

\section{Experiment}
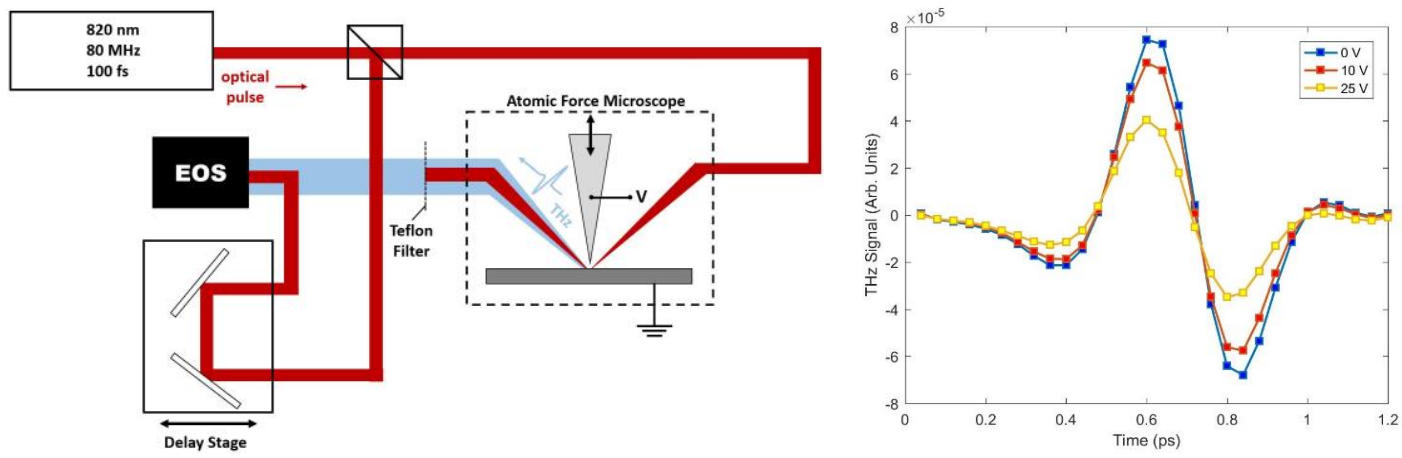

Fig.1: (a) Schematic of biased tip-enhanced LTEM. (b) Depleting THz waveforms in InAs A for $0 \mathrm{~V}$ bias, $10 \mathrm{~V}$ bias, and $25 \mathrm{~V}$ bias at $520 \mathrm{~nm}$ tapping amplitude

For nanometer-resolved LTEM, we couple a near-infrared (NIR) beam $(820 \mathrm{~nm}, 100 \mathrm{fs}, 80 \mathrm{MHz}$ repetition rate, $40 \mathrm{~mW}$ ) to a commercial near-field microscope (Neaspec) in tapping-mode. The tip of the AFM probe is an 80/20 PtIr alloy (Rocky Mountain Nanotechnology) which is approximately $80 \mu \mathrm{m}$ long and tapers to $20 \mathrm{~nm}$ wide at its apex. It taps at approximately $21 \mathrm{kHz}$, with a user-controlled amplitude on the order of hundreds of $\mathrm{nm}$. Nearinfrared pulses photoexcite charge carriers in a semiconductor wafer, which emits broadband $\mathrm{THz}$ radiation due to the sub-surface dipole induced by the photo-Dember effect [3]. The AFM tip serves both to confine the NIR pulses under the tip and out-couples the THz near-field signal, which we then detect using electro-optic sampling (EOS) and a lock-in amplifier locked to the tip tapping frequency [1]. Forward-scattered NIR light is blocked before the $\mathrm{THz}$ detection by a teflon filter which transmits the $\mathrm{THz}$ pulses.

Using an external DC supply, we apply a bias voltage between the tip and the sample, which is a bare semiconductor wafer. We then measure the emitted THz field. We compare results from two InAs wafers of different carrier concentrations and one InSb wafer. While THz sources have also been used in combination with Scanning 
Tunneling Microscopes (STM) to modulate tunneling currents and hence adding both time-resolution and improved spatial resolution to the STM technique [4], it is important to note that our study is distinct from this; we have explicitly verified that there is no tunneling current between the tip and sample.

\section{Results}

Waveforms for three values of applied DC bias in sample InAs A (p-doped, carrier concentration $\sim 10^{16} \mathrm{~cm}^{-3}$ ) are shown in Figure 1b. We observe significant signal depletion for increasing bias. As shown in Figure 2a, all three samples (InAs A, InAs B (p-doped, carrier concentration $\sim 10^{18} \mathrm{~cm}^{-3}$ ) and InSb (nominally undoped, carrier concentration $\left.\sim 10^{14} \mathrm{~cm}^{-3}\right)$ ) give similar results: the applied DC bias results in a decrease in the measured $\mathrm{THz}$ field, approximately independent of the sign of the bias.
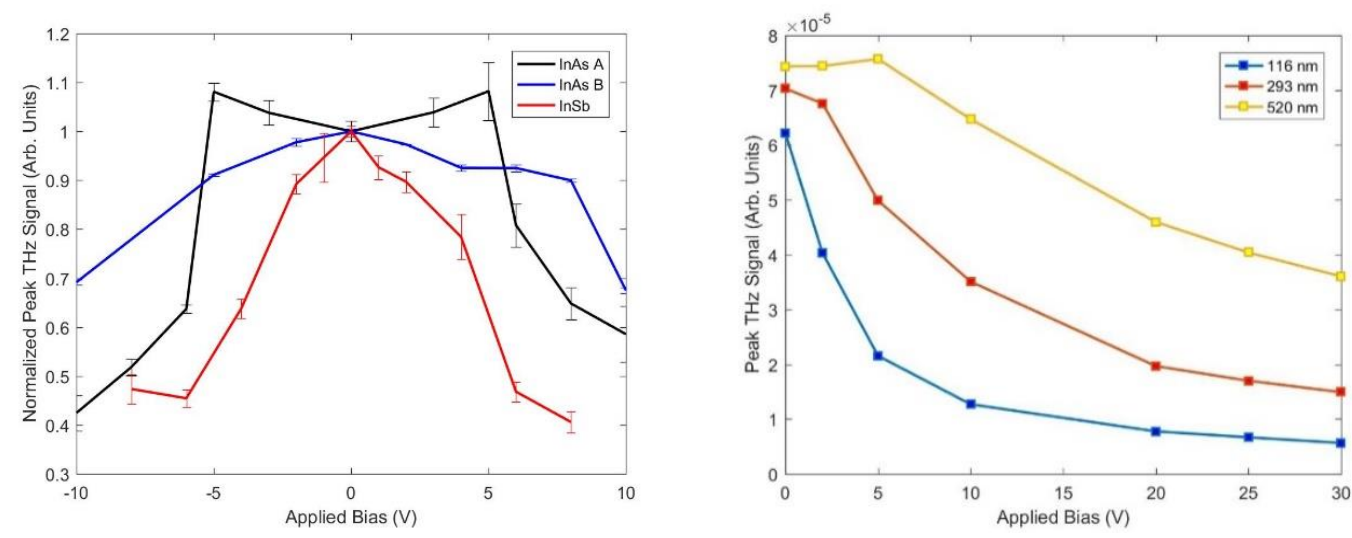

Fig. 2: (a) Peak THz field vs. DC bias, for 3 different samples (b) Peak THz signal emitted from InAs with increasing positive bias for three tip tapping amplitudes.

Figure $2 \mathrm{~b}$ shows the decrease in the peak THz field from sample InAs A with increasing positive bias, for three tapping amplitudes. As the tapping amplitude increases, we observe a larger peak field as well as a decreased sensitivity to the applied DC bias.

One possible cause of this DC bias dependence is the creation of a depletion region near the semiconductor surface; charge carriers may build up in the vicinity of the tip, screening the photo-excited THz dipole. It is also possible that the bias changes the local refractive index of the substrate, decreasing the sample's NIR absorption and therefore its $\mathrm{THz}$ emission. The higher tapping amplitude allows us to probe deeper into the substrate $[5,6]$ and overcome some of these carrier or refractive index effects. In future studies, we will perform further THz nanoscopy experiments to probe the wafers' local carrier dynamics around the tip.

\section{References}

[1] B. Knoll and F. Keilmann, "Near-field probing of vibrational absorption for chemical microscopy," Nature 399, 20154 (1999).

[2] P. Klarskov, H.Kim, V.L. Colvin, D.M. Mittleman, "Nanoscale Laser Terahertz Emission Microscopy," ACS Photon. 4, 2676-2680 (2017).

[3] P. Gu, M. Tani, S. Kono, K. Sakai, "Study of Terahertz Radiation from InAs and InSb,” J. Appl. Phys., Vol. 91 No.9, $5533-5537$ (2002).

[4] T. L. Cocker, V. Jelic, M. Gupta, S. J. Molesky, J. A. J. Burgess, G. D. L. Reyes, L. V. Titova, Y. Y. Tsui, M. R. Freeman, and F. A. Hegmann, "An Ultrafast Terahertz Scanning Tunneling Microscope," Nature Photon. 7, 620-625 (2013).

[5] R. Krutokhvostov, A.A. Govyadinov, J. M. Stiegler, F. Huth, A. Chuvilin, P. Scott Carney, and R. Hillenbrand, "Enhanced resolution in subsurface near-field optical microscopy," Opt. Express 20, 593-600 (2012).

[6] M. Eisele, T. L. Cocker, M. A. Huber, M. Plankl, L. Viti, D. Ercolani, L. Sorba, M. S. Vitiello, and R. Huber, "Ultrafast multi-terahertz nano-spectroscopy with sub-cycle temporal resolution," Nature Photon. 8, 841-845 (2014). 